REVISTA DE DERECHO UNED, NÚM. 17, 2015

\title{
LAS COMUNAS EN EL SISTEMA POLÍTICO VENEZOLANO
}

\author{
COMMUNES IN THE VENEZUELAN POLITICAL SYSTEM
}

\author{
Meralys Mata SANDOVAL \\ Doctora en Derecho. UNEG Venezuela
}

Resumen: El extinto Presidente Hugo Chávez Frías, en su afán por concentrar el máximo poder en el Ejecutivo Nacional, concretamente en su persona, comienza por querer instaurar en la República Bolivariana de Venezuela un Sistema Político inexistente en la Constitución de 1999, cual es un Sistema Socialista, no incluido entre sus ofertas de la campaña electoral de 1998, cuya idea lanza a la palestra por primera vez en el 2005, cuando comienza a hablar de «socialismo o transición al socialismo», y es de esta manera como proclama su programa de gobierno, haciendo la salvedad de que es un «proyecto en construcción», manejando su proyecto denominado «Socialismo del Siglo XXI», como es conocido en el mundo; en ese mismo año comienzan a organizarse los «Consejos Comunales» a fin de encausar la participación ciudadana (base constitucional Art. 70). Posteriormente constituye el llamado Poder Popular, la creación del Estado Comunal, cuyo núcleo social, económico, geográfico, político, territorial son las Comunas.

Palabras clave: Participación Ciudadana, Socialismo, Poder Popular, Estado Comunal. Comunas.

Abstract: The extinct President Hugo Chávez Frías, in its effort to concéntrate the máximum power in the National Executive, in his person; starts by wanting to establish a political system in the 1999 Constitution, which is a socialist system, not included among its offerings of the election campaignof 1998, which launches to the fore for the first 
time in 2005, when he starts talking about «socialism or transition to socialism", and is thus non-existent in the Bolivarian Republic of Venezuela as distinguishes following Government program Noting that it is a «construction Project», then managing their Project called «Socialism of the 21st century», as it is known in the world; in that same year beginsto organize the "comunal councils» in order to prosecute the participation citizen (art. 70 constitutional basis). It is later called people`s power, the creation of the Comunal State, whose social, economic, geographical, political, territorial core are communities.

Keyword: Participation Citizen. Socialism. Poder Popular, Been Communal, Communes.

Recepción original: 2/06/2015

Aceptación original: 6/07/2015

Sumario: I. Introducción. II. El Estado Federal en la Propuesta de Reforma Constitucional. III. Sobre la Ley Orgánica de los Consejos Comunales. IV. Transición desde el Estado Democrático Federal y Descentralizado al Estado Comunal.

"Es en la comuna donde reside la fuerza de los pueblos libres. Las instituciones comunales son a la libertad lo que las escuelas primarias vienen a ser a la ciencia; la ponen al alcance del pueblo; le hacen paladear su uso pacífico y lo habitúan a saberse de ellas.»

Alexis de Tocqueville

\section{INTRODUCCIÓN}

El extinto Presidente Chávez Frías bajo la idea de concentrar el poder en manos del Ejecutivo Nacional y de establecer en la República Bolivariana de Venezuela una forma de Estado Socialista -el llamado Socialismo del siglo XXI- avanzando hacia el debilitamiento progresivo de Instituciones establecidas en la Constitución de 1999, como son los Estados y las Alcaldías; desde el año 2005 procedió a crear instituciones, como es el caso de los Consejos Comunales, como expresión primaria de la organización ciudadana, y a promulgar una serie de leyes que facilitaran la instauración de un nuevo orden político-social-económico y territorial.

Usando como bandera la «participación ciudadana» se plantea la transferencia del poder desde los órganos representativos hacia el pueblo organizado en las nuevas estructuras creadas por el Gobierno Nacional en forma directa, y ello se hace en base a la «conveniente 
interpretación» de algunos artículos de la Constitución de 1999¹, principalmente el artículo 62 que contempla que «Todos los ciudadanos tienen el derecho a participar libremente en los asuntos públicos, directamente o por medio de sus representantes elegidos o elegidas...» -cuestión que se manifiesta en diferentes formas de participación ciudadana en lo político y lo económico, como es el caso de las «asambleas de ciudadanos» contemplada en el artículo 70-, y el artículo 184 que promueve la transferencia de ciertos servicios hacia las comunidades organizadas (la ley creará mecanismos abiertos y flexibles para que los Estados y los Municipios descentralicen y transfieran a las comunidades y grupos vecinales organizados los servicios que estos gestionen previa demostración de su capacidad para prestarlos...). Lo anterior se supone dentro sobre la base constitucional de un Estado Federal y Descentralizado, regido por «los principios de integridad territorial, cooperación, solidaridad, concurrencia y corresponsabilidad». Es así como el Gobierno Nacional empezó desde las comunidades a organizar unos «consejos» a los que se les asignó como función de promocionar la participación ciudadana en las cuestiones de la comunidad; así como también se empezaron a aplicar algunos postulados económicos del modelo socialista, entre ellos, la implementación de la propiedad colectiva.

Ya en el 2002 se promulga la Ley de los Consejos Locales de Planificación Pública ${ }^{2}$, en base a la cual se crea el Consejo Local de Planificación Pública, como un órgano mixto en el que se concentra la planificación de políticas públicas dentro del Municipio en el que participan representantes de la sociedad civil. Esta Ley contempla en su artículo 8 que «El Consejo Local de Planificación Pública promoverá la Red de consejos parroquiales y comunales en cada uno de los espacios de la sociedad civil que, en general, respondan a la naturaleza propia del municipio cuya función será convertirse en el centro principal de la participación y protagonismo del pueblo en la formulación, ejecución, control y evaluación de las políticas públicas, así como viabilizar ideas y propuestas para que la comunidad organizada las presente ante el Consejo Local de Planificación Pública. Una vez aprobadas sus propuestas y convertidas en proyectos, los miembros de los consejos parroquiales y comunales podrían realizar el seguimiento, control y evaluación respectivos...».

${ }^{1}$ Asamblea Nacional Constituyente (1999). Constitución de la República Bolivariana de Venezuela. Gaceta Oficial extraordinaria 5453. 24 de marzo de 2000. Venezuela.

${ }^{2}$ Ley de los Consejos de Planificación Pública, Gaceta Oficial n. 37509 del 20 de agosto de 2202 . 
Como puede verse el artículo 8 plantea la organización de los «consejos» desde dos aspectos diferentes, por un lado, la integración de la comunidad a través de los consejos comunales, y por otro, la integración de las parroquias, en los consejos parroquiales. Sin embargo, los consejos comunales se adoptan a partir de 2005 como instrumentos para la construcción del modelo de «transición al socialismo». En ese mismo año se dicta la Ley Orgánica del Poder Público Municipal $^{3}$, en la que, aunque no se detallan los consejos comunales, si se elimina la base legal de las asociaciones de vecinos, para encauzar toda participación ciudadana a través del Consejo Local. En el artículo 70 de esta ley se establece que los Municipios promoverían las «empresas de economía social», en el afán de orientar la participación ciudadana hacia el socialismo. Ahora bien, para el 2006 ya se habían constituido algunos Consejos Comunales como organizaciones de ciudadanos integrantes de unas comunidades, de manera informal, con el fin de participar en la construcción del estado socialista.; en ese mismo año es reformada la Ley de los Consejos Locales de Planificación Pública para fortalecer la participación de los Consejos Comunales en el Consejo Local y a su vez es sancionada la Ley de los Consejos Comunales (2006) ${ }^{4}$, en la misma no hay referencia al socialismo aunque el sistema estaba implícito en ella; se considera al consejo comunal como una sociedad de naturaleza civil integrante de una comunidad, conformando su máxima autoridad toda la comunidad, como "asamblea de ciudadanos y ciudadanas», con reconocimiento en el artículo 70 de la Constitución de 1999.

Según la Ley de los Consejos Comunales, resulta claro que, además de ser la figura necesaria para orientar la participación ciudadana dentro de la comunidad, actuando como órgano ejecutivo, también lo hace frente a los Poderes Públicos, especialmente ante el Municipio, realizando actividades a favor de la comunidad. La participación ciudadana en la comunidad no tenía carácter individual, sino colectivo. Los Consejos Comunales son asociados con el «poder Popular».

En este mismo año es reformada parcialmente la Ley Orgánica del Poder Público Municipal ${ }^{5}$, al objeto de adaptarla al marco institucional de los consejos comunales.

${ }^{3}$ Ley Orgánica del Poder Público Municipal. Gaceta Oficial n. ${ }^{\circ} 38204$, de 8 de junio de 2005.

${ }^{4}$ Ley de los Consejos Comunales, Gaceta Oficial n. ${ }^{\circ}$ 5.806, de 10 de abril de 2006.

${ }^{5}$ Reforma Ley Orgánica del Poder Público Municipal, Gaceta Oficial n. ${ }^{\circ} 5800$, de 10 de abril de 2006. 
En diciembre de 2006 resulta reelecto el Presidente de la República, lo que ayuda a la implementación del modelo socialista, no solo en el aspecto económico, sino también en lo político, consolidando un Poder Popular, no previsto en la estructura de la Constitución.

En 2007 empieza la configuración del «Poder Popular», como forma de participación ciudadana directa, sustituyendo así los mecanismos de la democracia representativa.

Con la idea de ahondar en la construcción del Socialismo y el afianzamiento del Poder Popular dentro de los poderes público, se promulga la Ley Orgánica del Poder Popular ${ }^{6}$, por la que todos los Ministerios pasan a llamarse Ministerios para el Poder Popular, como una demostración de que los mismos pasan a ser representantes directos del pueblo ${ }^{7}$.

Con esta estructura política-económica y social se llega a la propuesta de Reforma Constitucional, sancionada por la Asamblea Nacional en noviembre de $2007^{8}$, cuya esencia era la instauración de un Estado Socialista y Centralizado, con la denominación de Estado Comunal o Estado del Poder Popular. No obstante, al celebrarse una consulta popular, a través de un referéndum consultivo realizado el 7 de diciembre de 2007, es rechazada la propuesta.

En esta propuesta de Reforma de la Constitución, se concibe al Poder Popular como otra de las ramas del Poder Público, vendiendo la idea de que ese Poder estaría conformado por el pueblo como titular de la soberanía, vale decir, que el Poder Popular de los otros poderes representaría la expresión directa del pueblo soberano y soporte de los otros Poderes Públicos; ya que el Poder Popular se tendría como un poder originario, y a los otros Poderes Públicos como el poder derivado, tanto en sentido vertical como horizontal, en este orden de ideas la propuesta de Reforma refiriéndose al Poder Popular sostenía en su artículo 136 «...se expresa constituyendo a las comunidades,

${ }^{6}$ Ley Orgánica del Poder Popular, Gaceta Oficial n. ${ }^{\circ} 6011$ Extraordinario de 21 de diciembre de 2010.

${ }^{7}$ RONDÓN DE SANSÓ, H. «Inclusión del Poder Popular en la esfera de los poderes públicos» Anuario de Derecho Público, Año 1, Centro de Estudios de Derecho Público de la Universidad Monteávila, Caracas 2008, pág. 64.

${ }^{8}$ Propuesta de Reforma Constitucional de 2007: Allan R. BREWER-CARÍAS, Hacia la consolidación de un Estado Socialista, Centralizado, Policial y Militarista. Comentarios sobre el sentido y alcance de las propuestas de reforma constitucional 2007, Colección Textos Legislativos, n. ${ }^{\circ}$ 42, Editorial Jurídica Venezolana, Caracas 2007, 157 págs.; y La Reforma Constitucional de 2007 (Comentarios al proyecto inconstitucionalmente sancionado por la Asamblea Nacional el 2 de noviembre de 2007), Colección Textos Legislativos, n. ${ }^{\circ} 43$, Editorial Jurídica Venezolana, Caracas 2007, 224 págs.. 
las comuna y el autogobierno de los ciudadanos, a través de los consejos comunales, consejos de trabajadores y trabajadoras, consejos estudiantiles, consejos campesinos, consejos artesanales, consejos de pescadores y pescadoras, consejos deportivos, consejos de la juventud, consejos de adultos y adultas mayores, consejos de mujeres, consejos de personas con discapacidad y otros que señale la ley»

La propuesta de reforma constitucional de 2007 asumió que el Poder Popular era una rama territorial del Poder Público arraigada en la ciudad, núcleo básico del «Estado Socialista Venezolano» (artículo 16$)^{9}$. Poder Público que, según el citado artículo 136, no nace del sufragio ni de la elección, pues se trataría precisamente del poder originario, del poder derivado directamente de la soberanía del pueblo, Como se observa, hay una directa conexión entre el Poder Popular y la idea de poder constituyente: el Poder Popular es el poder constituyente en permanente actuación, según esta propuesta.

Importa y por muchas razones señalar, que el Poder Popular es esencial en la construcción del Estado Socialista, en cuanto a la participación ciudadana, la propuesta de reforma solo la toma en cuenta como un elemento más para la construcción de dicho modelo político, habida cuenta de que en el artículo 70 de la reforma se plantea los «... medios de participación y protagonismo del pueblo, en ejercicio directo de su soberanía y para la construcción del socialismo».

Ahora bien, habiendo sido rechazada la propuesta de reforma en diciembre de 2007, el Gobierno Nacional mantuvo su contenido esencial en el Plan de Desarrollo Económico y Social de la Nación 20072013, en el cual se ratifica el modelo socialista, la participación directa del pueblo, en efecto en el plan se le alude como «la democracia protagónica revolucionaria», también como "expresión genuina y auténtica de la verdadera democracia»; asimismo se mantiene en el Plan de la Nación como propuesta «construir la estructura institucional necesaria para el desarrollo del poder popular».

Otro hecho importante lo constituye la promulgación de la Ley Orgánica de los Consejos Comunales ${ }^{10}$, que deroga la Ley de los Consejos Comunales de 2006. Esta ley orgánica viene a consolidar la relación existente entre el Poder Popular y el socialismo. Establece en su artículo 2 que el consejo comunal tiene su base en la «comunidad

${ }^{9}$ LINARES BENZO, G. «Solo un Poder Público más. El Poder Popular en la Reforma 2007», en Revista de Derecho Público No 112. Estudios sobre la reforma constitucional, Caracas, 2007, págs. 101 y ss).

${ }^{10}$ Ley Orgánica de los Consejos Comunales, Gaceta Oficial n. 39335 del 28 de diciembre de 2009. 
organizada» y su propósito es «la construcción del nuevo modelo de sociedad socialista de igualdad, equidad y justicia social», en efecto, los modelos oficiales de los consejos comunales tienen como objeto la construcción del socialismo. Todo este proceso desde 2002 hasta 2009 no es más que la evolución hacia el Estado Comunal, que por supuesto tiene su base en el Poder Popular.

Dentro del marco del Plan de Desarrollo Económico y Social de la Nación ${ }^{11}$ 2007-2013 y en la búsqueda de conformar la estructura institucional, en el año 2010 se aprueban una serie de leyes, que fueron parte integrante de la Propuesta de Reforma Constitucional, no aceptada por el pueblo de Venezuela el 7 de diciembre de 2007.

\section{EL ESTADO FEDERAL EN LA PROPUESTA DE REFORMA CONSTITUCIONAL}

El día 15 de agosto de 2007, el Presidente de la República, actuando como Ejecutivo Nacional y el Ministro para el Poder Popular del Despacho de la Presidencia acuden ante la Asamblea Nacional para hacer la presentación del Proyecto de Reforma de la Constitución de la República Bolivariana de Venezuela ello en uso de la competencia que le confiere el artículo 342 de la misma, cuyo contenido es del siguiente tenor:

«La Reforma Constitucional tiene por objeto una revisión parcial de esta Constitución y la sustitución de una o varias de sus normas que no modifiquen la estructura y principios fundamentales del texto Constitucional. La iniciativa de la Reforma de esta Constitución podrá tomarla la Asamblea Nacional mediante acuerdo aprobado por el voto de la mayoría de sus integrantes, el Presidente o Presidenta de la República en Consejo de Ministros; o un número no menor del quince por ciento de los electores inscritos y electoras inscritas en el Registro Civil y Electoral que lo soliciten...».

En caso de que se diera una reforma sobre la estructura y principios fundamentales, se trataría de la propuesta de una nueva Constitución, y en ese caso se estaría ante los supuestos del artículo 348 de la Constitución, por lo que habría que convocar a una Asamblea Nacional Constituyente.

Ahora bien, el día 2 de diciembre de 2007, a instancias de la Presidencia de la República se realiza en Venezuela el referéndum para la

${ }^{11}$ Plan de Desarrollo Económico y Social 2007-2013. Publicación del Ministerio del Poder Popular para la Comunicación y la Información. Septiembre 2007. 
aprobación de la Reforma a la Constitución, cuyo resultado fue la negativa por parte del pueblo. Cabe señalar que desde inicios de ese año, la situación en el país era tensa, debido a lo que implicaba el contenido de la propuesta, a las amenazas que para la federación constituía la misma.

Analizando la propuesta se pueden realizar una serie de planteamientos. En lo atinente al Estado Federal descentralizado establecido en la Constitución vigente, puede observarse que continúa la tendencia hacia la re-centralización que ya se venía ejecutando por parte del Presidente de la República, así se observa la aprobación de un conjunto de leyes con la idea del supuesto desarrollo de los dispositivos constitucionales referentes a la federación. En tal sentido, están las modificaciones hechas al Título II del Espacio Geográfico y la División Política, en el Capítulo I Del territorio y demás espacios geográficos, concretamente en el artículo 11. A este artículo de le añade al final un último aparte, en el que se otorga facultad al Presidente de la República para crear Regiones Especiales Militares con objetivos estratégicos y de defensa, al tiempo que puede designar Autoridades Especiales si se tratara de situaciones de contingencia y desastres naturales, esto en concordancia con la propuesta contenida en los artículos 328 y 329, con referencia a la seguridad de la Nación y a la Fuerza Armada, al respecto se puede señalar lo siguiente:

- Puede verse como una disposición a crear normas excepcionales, cuestión que se ha dado a lo largo de la historia venezolana, con la intención de burlar el control sobre el poder.

- En este punto también se observa el propósito de militarizar la división político-territorial. En el caso planteado, si se tratara de previsiones por razones de seguridad este contenido hubiese sido planteado en el capítulo respectivo, e igualmente, en caso de que se tratara de Estados de Excepción.

En el Capítulo II, de la División Política, en el artículo 16 se observa la eliminación del encabezado del artículo, el cual se refiere a «... El territorio se organiza en Municipio.». La propuesta de reforma plantea la «nueva geometría del poder», lo que a decir del Presidente de la República constituye el llamado «cuarto motor» de la revolución. Es así como concibe la «unidad política primaria de la organización territorial nacional...como todo asentamiento poblacional dentro del Municipio, y conformada por áreas de extensiones geográficas denominadas Comunas»; concebidas a su vez, como «... las células geo-humanas del territorio y estarán conformadas por las Comunidades...»; al propio tiempo éstas conformarían "...el núcleo espacial 
básico e indivisible del Estado Socialista Venezolano, donde los ciudadanos y las ciudadanas comunes tendrán el poder para construir su propia geografía y su propia historia».

De lo anterior se infiere que el llamado Poder Popular generaría organizaciones que serían entendidas como «...formas de Autogobierno...», y, como otras expresiones, «...Democracia Directa». Este proceso de conformación de la Ciudad Comunal estará sujeto»...a un referéndum que convocará el Presidente de la República en Consejo de Ministros».

Asimismo, se establece la creación por decreto del Presidente en Consejo de Ministros, previo acuerdo de la mayoría simple de la Asamblea Nacional, de Provincias Federales, Ciudades Federales y Distritos Funcionales, "...así como cualquier otra entidad que establezca la ley».

El Distrito Funcional estará «...conformado por uno o más Municipios o Lotes Territoriales de estos, sin perjuicio del Estado al cual pertenezcan». Su creación se hará «... conforme a las características históricas, socio-económicas y culturales del espacio geográfico correspondiente.... e implicará "...la elaboración y activación de una Misión Distrital con el respectivo Plan Estratégico-funcional a cargo del Gobierno Nacional, con la participación de los habitantes de dicho Distrito Funcional y en consulta permanente con ...ellos.

En lo que respecta a la Ciudad Federal, su organización y funcionamiento será conforme a la ley respectiva, e implicará «...la activación de una Misión Local con su correspondiente plan estratégico de desarrollo».

El Poder Nacional es el encargado de nombrar las autoridades del Territorio Federal, el Municipio Federal y la Ciudad Federal, por el lapso máximo que establezca la ley «... y sujeto a mandatos revocables».

Por otra parte, las Provincias Federales son concebidas como «... unidades de agregación y coordinación de políticas territoriales, sociales y económicas a escala regional, siempre en función de los planes estratégicos nacionales y el enfoque estratégico internacional del Estado Venezolano»; la conformación de las mismas se hará mediante la anexión de Estados y Municipios, indistintamente, «...sin que sean menoscabados en las atribuciones que esta Constitución les confiere». Cuestión ésta que constituye una contradicción.

- Como puede verse, el contenido de esta norma constituye la desaparición de la histórica división territorial de Venezuela, 
como Estado federal; lo cual implica regresar al contenido de la Constitución de 1953, ya que los Municipios vendrían a ser una simple división de los Estados; sin mayor fundamento constitucional, con tendencia a desaparecer, después de pasar por una inexistencia real, con alcaldes sin funciones ni atribuciones y sin recursos.

- En cuanto al concepto de ciudad, supone desplazar al Municipio como célula fundamental de la organización del Estado, ya que su inserción junto con el concepto de Ciudad Federal, no produciría más que confusión, además de ser un concepto que no se ajusta con la idea que se tiene de ciudad, diferente a la idea de Municipio, aparte de que en el mismo texto se presenta a la Comuna como una célula geo-humana, y a las Comunidades como núcleo espacial básico e indivisible. Esta mescolanza de concepto, pereciera esconder una nueva organización del Estado, por supuesto, para nada federal, centralizada en exceso y con un carácter militarista.

- En el segundo aparte, la frase final, referida al "poder para construir su propia geografía e historia», constituye más bien una expresión demagógica, para sembrar la idea del poder popular.

- Por otra parte, no se trata de un precepto constitucional que regule una nueva forma de organización, ya existente, producto del desarrollo histórico de una sociedad, ni la que regula la naciente organización de un nuevo Estado, mediante pacto o contrato social. Simplemente se trata de la imposición de una voluntad con la idea de convertirla en institución, es decir, convertir el llamado Poder Popular en organización de formas de «autogobierno» y otras formas de «democracia directa», siempre sujetas al Poder Central, el verdadero poder.

- Otra idea contenida en aquella propuesta de reforma constitucional, es la expresión de Ciudad Comunal, solo entendible si se tratara de diferenciarla de la Ciudad Federal; en caso de que se tratara de la ciudad como unidad política primaria, es preocupante el hecho de que su creación esté sujeta a la convocatoria a referéndum por parte del Presidente de la República, lo cual confirma el carácter centralista de la organización del Estado.

- En lo atinente a la Provincia Federal, la Ciudad Federal y el Distrito Funcional, más que entidades de división políticoterritorial, son entidades operacionales, que permiten al Pre- 
sidente de la República adjudicarse directamente políticas sociales, económicas y de seguridad.

— De otra parte, el adjetivo «federal», en vez de ser una expresión retórica, instituiría la forma de acabar con la federación sin declararlo expresamente. Además nada garantiza que sean las únicas entidades que se pudieran crear, ya que por ley se pudieran crear otras, cuestión que hace dudar de su funcionalidad como instituciones, no así como instrumentos de operación.

- La grandilocuencia que expresa esta propuesta de reforma es tal que, el décimo aparte de este artículo, en su final expresa que las autoridades de dichas entidades, designadas por el Poder Nacional, es decir, por el Presidente de la República, son de «...mandatos revocables», expresión ésta que en la Constitución vigente se aplica a los funcionarios electos por votación popular, y como forma de participación ciudadana, a menos que fueran sometidos a revocatoria sus mandatos, por iniciativa popular y mediante referéndum revocatorio, por cierto que de esto no se hace alusión en el texto del artículo.

En el artículo 18, la organización de la ciudad de Caracas se elimina "...en un sistema de gobierno municipal a dos niveles...», como se señala en la Constitución vigente. Evidenciando la falta de técnica se incluyen en este artículo tres párrafos dedicados al sistema de ciudades, situación que debió ser motivo de un nuevo artículo, y dando continuidad al artículo 16; por tanto merece los comentarios siguientes:

- En base al sistema nacional de ciudades que se desarrollará en el marco de «...una política integral...», una Ley especial constituirá la unidad político territorial de la ciudad de Caracas.

- Puede verse en las consideraciones anteriores que en el sistema de ciudades descrito existe la tendencia a ir relegando la organización municipal, hasta su total desaparición; con la tendencia a la instauración planificada de un sistema de ciudades, esto no deja de ser una idea demostrativa de la imposición de una voluntad, que utiliza como referencia, una planificación enmarcada en una supuesta «....visión sistémica del país» que pudo haber sido incluida en la exposición de motivos, no así en el texto normativo. 
En el Título IV del Poder Público, Capítulo II de la Competencia del Poder Público Nacional, se incrementan las competencias del Poder Nacional en el Artículo 156, quitando competencia a los Estados ${ }^{12}$.

Se agregan nuevas competencias en favor del Poder Nacional (la creación, ordenación y gestión de Provincias Federales, Territorios Federales y Comunales -la llamada Nueva Geometría del Poder-; la gestión y administración de los ámbitos de la economía nacional y la transferencia a sectores de economía de producción social, colectiva o mixta, y la promoción, organización registro de los Consejos del Poder Popular -un poder sin autonomía-, así como a su apoyo técnico o financiero, lo que supone que el Presidencialismo y el re-centralismo se fortalecen.

Con el artículo 167, en lo atinente a los ingresos de los Estados, se ve afectada la distribución por Situado Constitucional, lo cual afecta a los Estados grandes (tomando en cuenta su población), y por supuesto no se establecen garantías a los municipios sobre el Situado Estadal ${ }^{13}$.

Con el artículo 168 se ven afectados los municipios y su autonomía y al respecto se puede plantear:

— En el texto se elimina: «Los municipios constituyen la unidad política primaria de la organización de la nación», lo cual es coherente con el concepto nuevo de ciudad señalado en la propuesta de reforma en el artículo 16.

${ }^{12}$ Los cambios se suscitan en los siguientes numerales: 8, Referido a la Fuerza Armada Nacional; 10: Incluye la ordenación y gestión del Distrito Federal, lo Estados y los Municipios; 15: Se refiere no solo a la creación y organización de los impuestos, sino también a su recaudación, desfavoreciendo a los Municipios; 17: Incluye las salinas y ostrales que eran los Estados, y ahora solo por delegación podrán los Estados gozar también del régimen de aprovechamiento de los minerales no metálicos; 22: Establece además unas políticas de control fiscal, que crean dudas acerca del papel de las Contralorías Estadales y Municipales; 27: Se asigna la conservación, administración y aprovechamiento de las autopistas y carreteras nacionales, que eran de los Estados; 28: Incluyen también los teleféricos; 30: En los servicios públicos incluye la telefonía por cable, inalámbrica Satelital, televisión por suscripción; 31: Es incluida la defensa de la integridad en el manejo de la política de Fronteras; 32: Incluye la organización y administración de la Contraloría General de la República, lo cual podría afectar el papel y funcionamiento de las Contralorías Estadales y Municipales; 33: Las materias tanto económica como financiera son incluida en la legislación nacional; 36: Además se agregan las competencias que no hayan sido atribuidas de forma expresa a los Estados y Municipios.

${ }^{13}$ El numeral 4 incrementa el situado al 25\% de los ingresos ordinarios, conforme a lo estimado, en aplicación a la Ley de Presupuesto anual, no como máximo sino como mínimo (antes era 15\% mínimo 20\% máximo), con la participación de los Territorios Federales, los Municipios Federales, las Comunas y las Comunidades, en la distribución, conforme a la ley. Eliminando la distribución por partes iguales o por población. El numeral 6 señala la eliminación del Fondo de Compensación Interterritorial. 
- Se declara obligatoria la participación ciudadana en la actividad de los Municipios, al propio tiempo se reduce a los Consejos del Poder Popular y los medios de producción socialistas, planteamiento éste que implica una contradicción más en lo que se refiere a los Consejos, porque en el texto se establece que los mismos son una organización del Estado, pero al propio tiempo los considera un medio de participación ciudadana.

- Elimina del texto la expresión: «Los actos de los Municipios no podrán ser impugnados sino ante los tribunales competentes, de conformidad con la Constitución y con la Ley», lo que mueve a pensar qué sucede con la autonomía de los mismos.

En el contenido del artículo 184 se señala que ha de ser la ley nacional la que instaure los mecanismos de transferencia a las comunidades organizadas, igualmente incluye al Poder Nacional, a las comunidades, los Consejos Comunales, las Comunas, entre otros entes del Poder Popular.

- En el numeral 1: Excluye tanto los servicios de salud, como los de educación, asimismo, los convenios como mecanismos de transferencias.

— En el numeral 2: Se descarta: «La participación de las comunidades, asociaciones de vecinos y $\mathrm{ONG}^{\prime} \mathrm{S}$ a la formulación de propuestas de inversión ... así como en la ejecución, evaluación y control ...»; y es reemplazada por: «La participación y asunción por parte de las organizaciones comunales de las gestión de las empresas públicas municipales y/o estadales».

— En el numeral 3: se agregan las expresiones «... desarrollo endógeno sustentable...» y «... que permitan la construcción de la economía socialista», que además de formar parte de la retórica de la propuesta de reforma en general, y de ser ambas propias de un programa de gobierno, no añaden nada a la intención original del constituyente de 1999; asimismo, se agrega la expresión «... empresas de propiedad social, colectiva y mixta...» en concordancia con la propuesta de reforma del artículo 115.

— Numeral 4: Se suprime: «... mediante mecanismos autogestionarios y cogestionarios ...». 
- Numeral 6: El texto de este numeral es cambiado en su totalidad, tomando en cuenta la «nueva geometría de poder», la cual es centralista y centralizadora, y conforme a ello no integraría el proceso participativo la creación de nuevos sujetos de descentralización, dentro del municipio, sino que sería por iniciativa de las comunidades, o en afinidad de éstas con las autoridades municipales.

- Numeral 7: También se sustituye por un nuevo texto. En cuanto a los establecimientos penales no habrá participación. El nuevo texto luce innecesario.

- Terminados los numerales se agregan dos apartes; en el primero, se establece la Asamblea de Ciudadanos como máxima autoridad, hoy Poder Popular; así como el planteamiento de que la ciudad es la unidad política primaria territorial, artículo 16, ante la ausencia de Exposición de Motivos, es de presumir que la ciudad sustituiría al Municipio, éste pasaría a ser una subdivisión de los Estados. En cuanto al segundo aparte, en clara demostración de lo que significa Justicia de Paz, se le otorga esta competencia a los Consejos Comunales.

En el artículo 185, que se refiere al Consejo Nacional de Gobierno, éste es sustituido por el Consejo Federal de Gobierno, el cual va a ser un órgano no permanente, con la función de evaluar los proyectos comunales, locales, estadales y provinciales, con una misión, si se quiere técnica, lo que conlleva a un retroceso y además una marcada recentralización.

La Reforma propuesta incide, de manera importante sobre el Estado Federal Descentralizado y los principios que lo rigen, según lo previsto en la Constitución de la República Bolivariana de Venezuela de 1999 (CRBV), entre ellos, los de autonomía, cooperación, participación y subsidiariedad:

- En lo atinente al Principio de Autonomía, es uno de los principios enfatizados en la Constitución. Así, el artículo 159 expresa: «los Estados son entidades autónomas...con personalidad jurídica plena»; y el artículo 168: "Los Municipios constituyen la unidad política primaria de la organización nacional, gozan de personalidad jurídica y autonomía...». El artículo 16 CRBV establece que «...la división político territorial será regulada por ley orgánica, que garantice la autonomía municipal y la descentralización político administrativa...». El mismo artículo, en la Reforma propuesta, no hace más 
que eliminar la garantía constitucional que posee la autonomía municipal y la descentralización político-administrativa en la CRBV. En la propuesta de reforma, el Municipio pierde su carácter de unidad política primaria, siendo sustituido por la ciudad.

Ahora bien, el Municipio, desde el punto de vista histórico-político y administrativo, en Venezuela siempre ha sido definido como la unidad política primaria; ese cambio obedece en la Reforma propuesta al «reordenamiento socialista» de las unidades poblacionales con fines geopolíticos.

En el artículo 16, se plantea desde el punto de vista constitucional uno de los cambios más profundos, ya que venía a ser uno de los cambios más profundos de la propuesta, en el camino a instaurar el Estado Socialista Venezolano. Este planteamiento representa la desmembración de la organización político-territorial de la nación, con una nueva geometría de poder que implica también una nueva distribución político-territorial, colocando entidades paralelas a los Estados y Municipios, limitando la autonomía, a los parámetros propuestos en la reforma.

Esta estructura del Estado Socialista sobrepone los principios fundamentales del Estado democrático y social de Derecho y justicia, contenidos en el artículo 2 de la CRBV. Cuando faculta al Presidente de la República para la creación de Provincias y Ciudades Federales, como unidades territoriales, económicas y sociales sujetas a los planes nacionales y con autoridades nombradas desde el poder central, se está dando una interpretación económica al término federal.

Por otra parte, daría énfasis a lo relativo a la transferencia de servicios a las comunidades organizadas como principio socialista en base al objetivo estratégico político nacional.

El federalismo ratifica que los Estados integrantes del pacto disponen de una competencia propia, fijada por la Constitución federal en materias legislativa, ejecutiva y jurisdiccional, que no puede ser disminuida por la intervención de otro nivel, ya que su heterogeneidad, multiplicidad y autonomía han de ser protegidas y amparadas por la propia Constitución, lo cual no se garantiza en la reforma propuesta.

La Constitución en el artículo 156 pone el control de los recursos en manos del Poder Público Nacional, así como otras competencias en ámbitos diferentes a favor del mismo; en el 157 en cuanto a otras facultades de los Estados y Municipios, pone en manos de la Asam- 
blea Nacional la atribución de determinadas materias del poder nacional, lo que significa que aquellos han revertido algunas competencia, sustentado por la mayoría oficialista parlamentaria.

En cuanto a la independencia de las fuentes de financiamiento de los subniveles territoriales, está comprometida, por depender del Poder Legislativo Nacional, por ser éste el creador de la ley de hacienda pública estadal, hay autores que consideran a la autonomía subordinada al poder legislador, no es una autonomía pura. De otra parte, una descentralización pura, exige una competencia tributaria para los subniveles, así como, la libertad para establecer de manera democrática la carga impositiva que le sea necesaria la situación.

La Reforma propuesta empeora la situación de los Estados porque les desmejora su competencia tributaria, como omite lo relativo al sistema de asignaciones económicas especiales (artículo 156, numeral 17), y no conforme con ello suprime el Fondo de Compensación Interterritorial (artículo185).

En la reforma propuesta se incluye el Fondo Nacional del Poder Popular (artículo 167); en lo que se refiere a las competencias municipales, incorpora los Consejos del Poder Popular (artículo 168) y otros entes del poder popular (artículo 184) a los cuales los recursos y gestión de servicios les serían descentralizados y transferidos por ley nacional.

- En lo referente al Principio de Cooperación, la Constitución de 1999 en su artículo 136 establece que «El Poder Público se distribuye entre el Poder Municipal, el Poder Estadal y el Poder Nacional. El Poder Público Nacional se divide en Legislativo, Ejecutivo, Judicial, Ciudadano y Electoral; en él se combinan la separación y la colaboración de poderes, cada una de las ramas del Poder Público tiene asignadas sus funciones propias, pero los órganos colaboran entre sí para cumplir los fines del Estado. Como es sabido las relaciones de coordinación se aplican con la idea de lograr los cometidos, de manera ordenada, para evitar la duplicidad de esfuerzos y recursos, mientras que el artículo 136 de la Reforma propuesta reprueba la colaboración entre los poderes públicos, lo que constituye uno de los cambios en las disposiciones fundamentales del poder público, en lo que se refiere a la distribución territorial con fines administrativos, propio de la concepción socialista del poder popular.

En el artículo 157, en concordancia con el artículo 185, se armoniza la participación de la Asamblea Nacional, como órgano del Poder 
Legislativo Nacional con el Consejo Federal de Gobierno, como órgano coordinador de la descentralización. Ambos están investidos de atribuciones que les permitan impulsar la transferencia de competencias desde el nivel central hacia los Estados y Municipios, lo que implica que ambos son indispensables para la promoción de las tendencias centrífugas del federalismo venezolano.

En la Reforma propuesta se presenta la transformación del Consejo Federal de Gobierno, partiendo desde su nombre, pasaría a llamarse Consejo Nacional de Gobierno, atendiendo más a la naturaleza nacional que federal, pasando a ser un órgano no permanente, y limitado a evaluar proyectos, lo que implica eliminar sus atribuciones como órgano planificador y coordinador de la descentralización, y por tanto menos federal y menos descentralizado político-territorialmente.

- El Principio de Participación constituye la participación una de las bases político-administrativas del gobierno, contenida en el artículo 6 del texto constitucional, conforme al carácter incluyente que poseen las asociaciones populares en la acción política y social, sin separarse de la descentralización ni del pluralismo político. Es de resaltar la importancia que tiene la intervención de los niveles políticos-territoriales, investidos de autonomía y de los grupos sociales organizados si se quiere crear la voluntad federal.

La Constitución de 1999, tanto en la exposición de motivos, como en su Preámbulo, y en el texto constitucional, establece la participación ciudadana como uno de sus principios fundamentales. El artículo 70 , señala que es indispensable en los ámbitos social, político y económico, al punto de extenderla al proceso de formación, ejecución y control de la gestión pública.

La propuesta de Reforma plantea la participación como un elemento del proceso de construcción del socialismo (artículo 70), ya que se incrementan las formalidades para la participación y el protagonismo del pueblo en ejercicio de la soberanía. Evidentemente se aplica un modelo de participación socialista, lo cual afecta otro de los principios fundamentales cual es el pluralismo político, establecido en los artículos 2 y 6 del texto constitucional, en el Título de los Principios Fundamentales, y que no podrán modificarse por medio de una reforma constitucional.

La descentralización implica una fórmula para acercar el poder a los ciudadanos; lo que quiere decir que la descentralización y la participación son instrumentos del proceso evolutivo político, económico 
y social venezolano, lo que destaca la importancia de la descentralización participativa.

En el artículo 158 de la Reforma Constitucional propuesta se busca eliminar la descentralización y sustituirla por la participación protagónica del pueblo, en la búsqueda de implementar una democracia socialista, tomando como elemento el Poder Popular, cabe destacar que este no nace del sufragio ni de elección popular alguna, sino como una condición de los grupos humanos organizados como base de la población, esto a partir de la instauración jurídico- política del modelo socialista, concentrando el poder en el poder nacional, grupos que como poder originario de base poblacional, terminan conformando las comunidades, comuna y ciudades, impuestas y dependientes del poder nacional, en el modelo socialista.

- El Principio de Subsidiariedad, es impuesto en la Constitución de 1999 como un concepto innovador con destacada naturaleza participativa, constituye un principio básico de la descentralización, promociona la transferencia de servicios hacia los entes políticos territoriales, a las comunidades y grupos vecinales organizados.

La Subsidiariedad arroga responsabilidades a organizaciones ubicadas en niveles intermedios e inferiores, cercanos a los ciudadanos. Este principio no está previsto expresamente en la Exposición de Motivos, ni en el artículo 4 que caracteriza a la República Bolivariana de Venezuela como Estado federal descentralizado; más sin embargo está contenido expresamente en el artículo 165 de la Constitución de la República Bolivariana de Venezuela; por lo que está inmerso en los fines, valores, y en la norma constitucional cuando se refiere a la participación, a las comunidades y a los grupos vecinales organizados en relación a la descentralización y transferencia de servicios, prevista en el artículo 184, al referirse a la descentralización participativa y protagónica; por lo que se prevé la transferencia Estado-Municipio y la transferencia Estado-Municipio-Comunidad.

El encabezado del artículo 184 expresa: «La ley creará mecanismos abiertos y flexibles para que los Estados y Municipios descentralicen y transfieran a las comunidades y grupos vecinales organizados los servicios que éstos gestionen previa demostración de su capacidad para prestarlos»; en el numeral 6 admite la creación de «nuevos sujetos de descentralización a nivel de las parroquias, las comunidades...». Aunque este artículo es el soporte constitucional para los Consejos Comunales, en la ley que los crea, es omitido. 
Igualmente, el Municipio debería seguir siendo el órgano que relaciona directamente con los Consejos Comunales y no una comisión nacional presidencial, pues además de separar, violenta las instancias establecidas en los artículos 157, 165 y 184 de la CRBV, vale decir, la relación República-Estado-Municipio-Comunidad.

El Gobierno Nacional promulga una serie de leyes (Decretos Leyes de carácter Orgánico) con el objeto de darle basamento legal a ese Estado Comunal, entre las que se pueden mencionar:

— En el 2008: La Ley Orgánica de la Administración Pública y la Ley Orgánica de la Comisión Central de Planificación.

— En el 2009: Ley Orgánica de los Consejos Comunales.

— En el año 2010: Ley Orgánica y Reglamento del Consejo Federal de Gobierno, Ley Orgánica del Poder Popular, Ley Orgánica de las Comuna (define el Estado Comunal), Ley Orgánica del Sistema de Economía Comunal, Ley Orgánica de Contraloría Social, Ley Orgánica de Planificación Pública y Popular, Reforma de la Ley de Consejos Estadales de Planificación y Coordinación, Ley Orgánica de los Consejos Locales de Planificación, Ley Orgánica del Poder Público Municipal.

— En el año 2012: Ley Orgánica para la Gestión Comunitaria de Competencias, Servicios y otras Atribuciones. (Decreto con Rango, Valor y Fuerza de Ley Orgánica para la Gestión Comunitaria de Competencias, Servicios y otras atribuciones).

Al Estado Comunal que plantea el Socialismo propuesto por el Gobierno para Venezuela, cuya implementación definitiva se realiza con la entrada en vigor de la Ley Orgánica de las Comunas, se le pueden atribuir las siguientes características:

- Supone un nuevo ordenamiento territorial cuya son las Comunas y los Distritos Motores de Desarrollo.

- La existencia de un modelo de economía comunal basado en una Planificación Centralizada, en la Propiedad Social y el trueque.

- Una nueva forma de participación tutelada en la Gestión Gubernamental.

— Su base técnica se encuentra en el Plan de Gobierno 2013/2019, conocido como Proyecto Nacional Simón Bolívar. 
Por otra parte la conformación del Ministerio del Poder Popular para las Comunas y Protección Social ${ }^{14}$ (17 de septiembre de 2009), con competencia sobre esta estructura territorial local, con dependencia directa del Poder Central y con «misión de cercar» tanto al municipio, como a cualquier otra entidad territorial municipal.

Con la implementación de las Comunas, la Gestión Comunitaria de Competencias, Servicios y otras Atribuciones, la conformación del Ministerio del Poder Popular para las Comunas y Protección Social y Promulgación de los Decretos Leyes detallados, se echa el andamiaje legal y funcionamiento del Estado Comunal en paralelo al Estado previsto en la Constitución.

\section{SOBRE LA LEY ORGÁNICA DE LOS CONSEJOS COMUNALES}

Sobre la base de la «Participación Protagónica» de los ciudadanos y el contenido de la Constitución de la República Bolivariana de Venezuela ${ }^{15}$ se le establece al pueblo el derecho de participar libremente en los asuntos públicos, en cuanto a la formación, ejecución y control de la gestión pública, considerando que es el medio necesario para alcanzar el protagonismo y a los fines de garantizar su máximo desarrollo, ya sea individual o colectivo; para ello se desarrolló la Ley Orgánica de las Consejos Comunales, sancionada y publicada en Gaceta Oficial n. ${ }^{\circ} 39335$ del 28 de diciembre de 2009.

La mencionada ley señala en el artículo 1, como objetivo el siguiente «..regular la constitución, conformación, organización y funcionamiento de los Consejos Comunales como una instancia de participación para el ejercicio directo de la soberanía popular y su relación con los órganos y entes del Poder Público para la formulación, ejecución control y evaluación de las políticas públicas, así como los planes y proyectos vinculados al desarrollo comunitario».

Mientras, en el artículo 2 plantea la definición de lo que a los efectos de la ley son los Consejos Comunales y al respecto dice:

«...en el marco constitucional de la democracia participativa y protagónica, son instancias de participación, articulación e integración entre los ciudadanos, ciudadanas y las diversas organizaciones comunitarias, movimientos sociales y populares, que permiten al pueblo organizado

${ }^{14}$ Revista de Derecho Público n. ${ }^{\circ}$ 130/2012, págs. 131-132. Facultades de este Ministerio para el Poder Popular para las Comunas.

${ }^{15}$ Artículo 168, segundo aparte «Las actuaciones del Municipio en el ámbito de sus competencias se cumplirán incorporando la participación ciudadana al proceso de definición y ejecución de la gestión pública y al control y evaluación de sus resultados, en forma efectiva, suficiente y oportuna, conforme a la ley». 
ejercer el gobierno comunitario y la gestión directa de las políticas públicas y proyectos orientados a responder a las necesidades, potencialidades y aspiraciones de las comunidades, en la construcción del nuevo modelo de sociedad socialista de igualdad, equidad y justicia social.»

En el artículo 3 se señala que la organización, funcionamiento y acción de los consejos comunales se rige por los principios y valores de participación, corresponsabilidad, democracia..., con el fin de establecer la base sociopolítica del socialismo que consolide un nuevo modelo político, social, cultural y económico».

En el artículo 4 se marcan cada una de las palabras claves utilizadas para definir lo que pudieran ser los elementos que conforman la estructura de los Consejos Comunales, es así como se define ${ }^{16}$ : Comunidad: constituye el «núcleo espacial básico e indivisible constituido por personas y familias que habitan en un ámbito geográfico específico»; Ámbito Geográfico: conforma el «territorio que ocupan los habitantes de la comunidad, donde se establecen los límites geográficos avalados por la Asamblea de Ciudadanos»; Base Poblacional de la Comunidad: es el «número de habitantes de la comunidad»; Organizaciones Comunitarias: son las « organizaciones que existen o pueden existir en el seno de las comunidades»; Comité de Trabajo: conformado por «el colectivo o grupo de personas organizadas para ejercer funciones específicas»; Vocero o Vocera: es el «ciudadano electo, mediante proceso de elección popular a fin de coordinar el funcionamiento del Consejo Comunal así como también las decisiones de la Asamblea de Ciudadanos»; Proyectos Comunitarios: son las «acciones dirigidas a lograr uno o varios objetivos, los cuales deben contener una programación de acciones determinadas en el tiempo, recursos y los resultados esperados»; Áreas de Trabajo: es el «ámbito de gestión que constituyen en concordancia con las particularidades, problemas más relevantes, estas áreas de trabajo agrupan varios comités de trabajo»; Plan Comunitario de Desarrollo Integral: constituido por un documento técnico que permite identificar las potencialidades, limitaciones y prioridades, orientados éstos al desarrollo de la comunidad»; Gestión: son las "acciones exigidas al cumplimiento de los objetivos y metas aprobados por los ciudadanos»; Economía Comunal": son las «acciones vinculadas a actividades de producción, distribución, intercambio y consumo de bienes y servicios desarrolladas en las comunidades bajo la figura de Propiedad Social al servicio de sus necesidades, de acuerdo con lo establecido en el Sistema Centralizado de Planificación, y en el Plan de Desarrollo Económico de la Nación»;

${ }^{16}$ Ley Orgánica de los Consejos Comunales, G. O. n. ${ }^{\circ} 39.377$ del 2 de marzo de 2010.

(C) UNED. Revista de Derecho UNED, núm. 17, 2015 
y, Redes Socio Productivas: es la «articulación de los procesos productivos de las organizaciones socio productivas de las organizaciones socio productivas comunitarias».

En los 33 artículos que contiene la Ley Orgánica de los Consejos Comunales se encuentra desplegado todo el funcionamiento de los Consejos Comunales, órganos creados a instancia del Extinto Presidente de la República, en abierto incumplimiento al texto constitucional, excusándose en la Participación Ciudadana.

Los Consejos Comunales constituyen la primera expresión del Estado Comunal; desde el punto de vista jurídico es la asociación de personas integrantes de una comunidad, representada por una "asamblea de ciudadanos y ciudadanas», que constituye la instancia deliberativa y es la máxima autoridad junto a la Unidad Ejecutiva, con los Comités como órgano ejecutor que están conformados por los Voceros que son elegidos directamente por la Asamblea.

Los Consejos Comunales vienen a ser instancias territoriales, cuya actividad está circunscrita a la comunidad en la cual se conforma. El territorio de los consejos comunales es mucho menor que el de las Parroquias que conforman los Municipios, de modo que en una Parroquia existen varios Consejos Comunales que no podrán cubrir un mismo ámbito geográfico; la actividad que realizan no está definida en la Ley, y como se establece en el artículo 2 se trata de gobiernos comunitarios, es decir, de «autogobiernos». De allí pues que el Consejo Comunal es la organización que atiende directamente las cuestiones propias de la comunidad, sin que para ello intervengan los órganos.

\section{TRANSICIÓN DESDE EL ESTADO DEMOCRÁTICO FEDERAL Y DESCENTRALIZADO AL ESTADO COMUNAL}

A raíz de los resultados de la Elección presidencial de 7 de octubre de 2013 se da inicio a la consolidación del Estado Comunal en Venezuela; lo que representa el planteamiento de un Modelo distinto al Modelo Federal y Descentralizado desarrollado en la Constitución de la República Bolivariana de Venezuela de 1999.

Este modelo conlleva a una nueva organización territorial, a un nuevo régimen de propiedad y por supuesto a una nueva forma de participación ciudadana, la implementación paulatina del Estado Comunal, lo que implica el rompimiento y desmantelamiento de la democracia participativa que aún existe en Venezuela, pero, puede 
considerarse que su instauración constituye la existencia de un Estado Paralelo al plasmado en la Constitución.

La implementación del Estado Comunal tiene sus antecedentes en el País y paulatinamente se fueron dando las condiciones para su instauración, entre ellos pueden mencionarse los siguientes:

- Con la creación del «Mapa de los 10 Objetivos Estratégicos planteados por el Presidente en el año 2004, se inicia la ruptura con la descentralización.

- La Propuesta de una nueva ordenación territorial presentada por el entonces presidente, en el 2005, la cual plantea la existencia de los 23 Estados y la creación de 8 Regiones.

- En el 2006 durante la Campaña Electoral se plantea el desarrollo del Socialismo, hecho efectivo con la iniciativa de Ley de las Comunas.

— En el año 2007 el presidente da a conocer «Los 5 Motores Socialista»: plantea su Propuesta de Reforma Constitucional, Habilitante, la Nueva Geometría del Poder, Moral y Luces y Explotación del Poder Comunal.

- Creación del Ministerio de las Comuna, Plan de la Nación (Socialista) 2013/2019 y la Misión 13 de Abril en 78 Municipios del país, todo esto en el año 2008.

— En el año 2009 se reúne el Consejo Presidencial de Ministros, con la creación de 5 Vicepresidencias. El Tribunal Supremo de Justicia asume una actitud, a través de algunas sentencias que dan al traste con la división de poderes (interpretaciones de la Sala Constitucional), se aprueba la Ley Orgánica de los Consejos Comunales, se posponen las elecciones municipales.

— Durante el año 2010 se constituye la Comisión Presidencial de las Comunas. Se promulga la Ley y reglamento del Consejo Federal de Gobierno (con 10 años de atraso), se promulgan Leyes del Poder Popular, se elimina la elección directa de las Juntas Parroquiales.

- Se aprueba la Ley de Gestión Comunitaria de Competencias, y por último se lanza la nueva candidatura a reelección del Presidente, con la promesa de consolidar el socialismo.

Con la implementación de las Comunas, la Gestión Comunitaria de Competencias, Servicios y otras Atribuciones, la conformación del Ministerio del Poder Popular para las Comunas (17 de septiembre 
de 2009), con competencia sobre esta estructura territorial, dependiendo directamente del Poder Central, cuya «misión es cercar» tanto al Municipio, como cualquier otra entidad territorial municipal; y Protección Social y Promulgación de los Decretos Leyes detallados, se echa el andamiaje legal y funcionamiento del Estado Comunal en paralelo al Estado previsto en la Constitución de 1999

\section{SOBRE LAS COMUNAS}

La Comuna constituye una de las instancias básicas del Estado Comunal, instituida en el 2010 conforme a la ley como una «entidad local socialista», establece el artículo 57: "“Es un espacio socialista que, como entidad local, es definida por la integración de comunidades vecinas con una memoria histórica compartida, rasgos culturales, usos y costumbres, que se reconocen en el territorio que ocupan y en las actividades productivas que le sirven de sustento, y sobre el cual ejercen los principios de soberanía y participación protagónica como expresión del poder popular, en concordancia con un régimen de producción social y el modelo de desarrollo endógeno y sustentable, contemplado en el Plan de Desarrollo Económico y Social de la Nación”.

Se plantea la necesidad de aclarar la expresión contenida en este artículo puesto que según la Reforma de la Ley Orgánica del Poder Público Municipal de $2010^{18}$, las «entidades locales» son las que funcionan dentro del perímetro de los Municipios, con ejercicio de la autonomía municipal. En efecto, el artículo 5 de la reforma realizada a la Ley Orgánica del Poder Público Municipal sancionada en 2010 establece lo siguiente: «Los municipios y las entidades locales se regirán por las normas constitucionales, las disposiciones de la presente Ley, la legislación aplicable, las leyes estadales y lo establecido en las ordenanzas y demás instrumentos jurídicos municipales.

Las ordenanzas municipales determinarán el régimen organizativo y funcional de los poderes municipales según la distribución de competencias establecidas en la Constitución de la República, en esta Ley y en las leyes estadales. Se exceptúan las comunas de estas disposiciones, por su condición especial de entidad local, reguladas por la legislación que norma su constitución, conformación, organización y funcionamiento».

${ }^{17}$ Ley m Orgánica de las Comunas. Gaceta Oficial 6011 Extraordinario, del 21 de diciembre de 2010.

${ }^{18}$ Reforma de la Ley Orgánica del Poder Público Municipal de 2010 Gaceta Oficial n. ${ }^{\circ} 6.015$, del 28 de diciembre 
Por otra parte, la misma reformada Ley en el artículo 19, pauta lo siguiente: «Además de los municipios son entidades locales territoriales:

1. La comuna.

2. Los distritos metropolitanos.

3. Las áreas metropolitanas.

4. Las parroquias y demás demarcaciones dentro del territorio del Municipio, tales como la urbanización, el barrio, la aldea y el caserío.

Los supuestos y condiciones establecidos en esta Ley, para la creación de estas demarcaciones entro del territorio del Municipio, así como los recursos de que dispondrán, concatenadas a las funciones que se les asignen, incluso su participación en los ingresos propios del Municipio, deberán ser considerados en la ley estadal que la desarrolle.

La comuna, como entidad local de carácter especial que se rige por su ley de creación, puede constituirse dentro del territorio del Municipio o entre los límites político administrativo de dos o más municipios, sin que ello afecte la integridad territorial de los municipios donde se constituya (negritas nuestras).

Por su parte, el artículo 33, último aparte (numeral 7) de la misma Ley, establece:

«...Los requisitos para la creación de la comuna, en el marco de su régimen especial como entidad local, se regirán por lo establecido en la Ley Orgánica de las Comunas.»

Resulta claro que la organización de la comuna puede equiparse a la organización del consejo comunal, de hecho, cuando se alude a las personas que conforman las comunidades integrantes de la comuna, conforman el «Parlamento Comunal», En el artículo 21 define al Parlamento Comunal como: « La máxima autoridad del autogobierno en la comuna; y sus decisiones se expresan mediante la aprobación de normativas para la regulación de la vida social y comunitaria, coadyuvar con el orden público, la convivencia, la primacía del interés colectivo sobre el interés particular y la defensa de los derechos humanos, así como en actos de gobierno sobre los aspectos de planificación, coordinación y ejecución de planes y proyectos en el ámbito de la comuna». 
Por otra parte, en lo que se refiere a la conformación y elección de los miembros del Parlamento, en el artículo 23 se plantea: «...El Parlamento Comunal está integrado de la siguiente manera:

1. Un vocero o vocera y su respectivo suplente, electo o electa por cada consejo comunal de la Comuna

2. Tres voceros o voceras y sus respectivos suplentes, electos o electas por las organizaciones socio-productivas.

3. Un vocero o vocera y su respectivo suplente, en representación del Banco de la Comuna.

El período de los voceros y voceras ante el Parlamento Comunal es de tres años, pudiendo ser reelectos

Evidentemente se trata de una estructura de tipo piramidal, ya que a partir de los voceros del consejo comunal, se construye el Parlamento, el cual elegirá a los voceros del órgano ejecutivo de la Comuna, cuyo nombre es el Consejo Ejecutivo, que además estará integrado por un vocero electo por los voceros de las organizaciones socio-productivas ante el Parlamento Comunal (artículo 27). Desde luego que la organización de la comuna es más compleja, porque incluye los Comités de Gestión, el Consejo de Planificación Comunal, el Consejo de Economía Comunal, el Banco de la Comuna y el Consejo de Contraloría Comunal, tal como está contenido en el artículo 4 de la Ley respectiva. La estructura de la comuna se inicia a partir de los consejos comunales, pero, en un ámbito local, resumiendo el consejo comunal se corresponde con la Parroquia, en tanto que la comuna equivale al Municipio.

Sin duda que, en la organización de la comuna se nota el propósito de reproducir la estructura del Estado, lo que se evidencia de las denominaciones del Estado Comunal, por ejemplo el Parlamento. En efecto, la comuna puede dictar sus normas jurídicas, así vemos que la Carta Fundacional es la Constitución de la Comuna y las Cartas Comunales contienen las normas que se crean desarrollando su funcionamiento.

Establece la Ley en el mismo artículo 4: «La Carta Fundacional: Instrumento aprobado en referendo popular, donde las comunidades expresan su voluntad de constituirse en comuna, en su respectivo ámbito geográfico, contentiva de la declaración de principios, censo poblacional, diagnóstico sobre los principales problemas y necesidades de su población, inventario de las potencialidades económicas, sociales, culturales, ambientales, y opciones de desarrollo». 
Así como: «Cartas Comunales: Instrumentos donde se establecen las normas elaboradas y aprobadas por los habitantes de la comuna en el parlamento comunal, con el propósito de contribuir corresponsablemente en la garantía del orden público, la convivencia y la primacía del interés colectivo sobre el interés particular, de conformidad con la constitución y las leyes de la república». Ello implica que se trata de normas jurídicas producto del ejercicio directo de la soberanía ejercida por la comuna y que no derivan de la representación popular.

Por otra parte, la comuna en ningún caso está regida por un autogobierno, como lo plantea la Ley, es decir, no es una instancia autónoma, puesto que debe ser reconocida por el Gobierno Nacional para adquirir su personalidad jurídica, y además, tiene por objeto ley la «construcción del Socialismo».

Dentro de este marco también establece la Ley Orgánica de las Comunas, el verdadero propósito de la Comuna, así lo señala el artículo 6: «La Comuna tiene como propósito fundamental la edificación del estado comunal, mediante la promoción, impulso y desarrollo de la participación protagónica y corresponsable de los ciudadanos y ciudadanas en la gestión de las políticas públicas, en la conformación y ejercicio del autogobierno por parte de las comunidades organizadas, a través de la planificación del desarrollo social y económico, la formulación de proyectos, la elaboración y ejecución presupuestaria, la administración y gestión de las competencias y servicios que conforme al proceso de descentralización, le sean transferidos, así como la construcción de un sistema de producción, distribución, intercambio y consumo de propiedad social y la disposición de medios alternativos de justicia para la convivencia y la paz comunal, como tránsito hacia la sociedad socialista, democrática, de equidad y justicia social (negritas nuestras).

Asimismo, en el artículo 7 se señalan las finalidades de la Comuna, entre ellas: 1. Desarrollar y consolidar el estado comunal como expresión del poder popular y soporte para la construcción de la sociedad socialista. 2. Conformar el autogobierno para el ejercicio directo de funciones en la formulación, ejecución y control de la gestión pública. 3. Promover la integración y la articulación con otras comunas en el marco de las unidades de gestión territorial establecidas por el Consejo Federal de gobierno. 4. Impulsar el desarrollo y consolidación de la propiedad social. 5. Garantizar la existencia efectiva de formas y mecanismos de participación directa de los ciudadanos y ciudadanas en 
la formulación, ejecución y control de planes y proyectos vinculados a los aspectos territoriales, políticos, económicos, sociales, culturales, ecológicos y de seguridad y defensa. 6. Promover mecanismos para la formación e información en las comunidades. 7. Impulsar la defensa colectiva y popular de los derechos humanos.

Finalmente, a propósito de todo lo expuesto pudiera señalarse lo siguiente:

- Al crearse «la comuna», el legislador cae en el desconocimiento de las entidades locales constitucionalmente establecidas; tal como lo es el Municipio (artículo 16 y 168 de la Constitución), la mancomunidad (artículo 170 ejusdem) y la parroquia (artículo 173 ejusdem).

- Ignorando el contenido de la Constitución se establece una nueva entidad en la organización del Estado denominada «la comuna», además ubicándola entre las entidades de base territorial local; cometiendo la aberración de sustraerla del régimen al que el Constituyente sometió a todas las entidades locales, como está previsto en el artículo 169 de la Constitución, además, complementado por el contenido del artículo 5 de la Ley Orgánica del Poder Público Municipal.

- Sin duda, «la comuna» es una entidad de cualquier naturaleza, menos local, dado que, si no hay la obligación de cumplir con el régimen instituido en el artículo 169 de la Constitución para las entidades locales, desarrollado en el artículo 5 de la Ley Orgánica del Poder Público Municipal, mal puede considerarse como una legítima o genuina entidad local.

- Por lo demás; cuando se exime a «la comuna» del cumplimiento del ordenamiento general que rige al Poder Público Municipal y someterla a una ley nacional especial no prevista en la Constitución y distinta de la Ley Orgánica del Poder Público Municipal están siendo afectadas las competencias de los Estados para organizar sus municipios y demás entidades locales, competencias amparadas por la Constitución, así como por las disposiciones de la Ley Orgánica del Poder Público Municipal, y como señala la Constitución y leyes estadales, según lo previsto en el mencionado artículo 169 de la Constitución y contenido de los artículos 5, 9 y 19 de la Ley Orgánica del Poder Público Municipal, desde el año 2005. 
- Por otra parte, cuando el legislador incluye a «la comuna» entre las entidades locales de base territorial y al mismo tiempo la exime del régimen jurídico al que se encuentran sometidas éstas, está afectando la garantía institucional de la autonomía municipal, ya que impide que los municipios puedan cumplir con el ejercicio de sus competencias, como por ejemplo, la de regular las entidades locales a través de ordenanzas; asimismo, impide que los municipios puedan regular "la comuna» en cuanto a su creación, organización y funcionamiento, ello contraviniendo el artículo 168, numeral 2 de la Constitución.

\section{BIBLIOGRAFÍA}

Asamblea Nacional Constituyente (1999). Constitución de la República Bolivariana de Venezuela. Gaceta Oficial extraordinaria 5453. 24 de marzo de 2000. Venezuela.

Asamblea Nacional de la República Bolivariana de Venezuela (2009a). Ley de reforma parcial de la Ley Orgánica de Descentralización. Gaceta Oficial n. ${ }^{\circ}$ 39.140. 17 de marzo de 2009. Venezuela.

- (2010). Ley de Consejo Federal de Gobierno. Gaceta Oficial extraordinaria n. ${ }^{\circ}$ 5963. 22 de febrero de 2010. Venezuela.

- (2007). Proyecto de Reforma Constitucional. Caracas. Venezuela.

Constitución de la República Bolivariana de Venezuela con la enmienda n. ${ }^{\circ}$ 1. Gaceta Oficial n. ${ }^{\circ} 5.908$ Extraordinario de 19 de febrero de 2009. Artículo 187.

Ley Orgánica de las Comunas. Gaceta Oficial n. ${ }^{\circ} 6.011$ Extraordinario de 21 de diciembre de 2010.

Ley Orgánica de los Consejos Comunales. Gaceta Oficial n. ${ }^{\circ} 39.377$ de 2 de marzo de 2010. Gaceta Oficial n. ${ }^{\circ} 39.335$ de 28 de diciembre de 2009.

Ley Orgánica de Régimen Municipal. Gaceta Oficial n. ${ }^{\circ} 4.109$ Extraordinario de 15 de junio de 1989.

Ley Orgánica de Régimen Municipal. Reglamento Parcial n. ${ }^{\circ} 1$ sobre Participación de la Comunidad. Caracas. Venezuela.

Ley Orgánica del Consejo Federal de Gobierno. Gaceta Oficial Extraordinario n. ${ }^{\circ} 5.963$ del 22 de febrero de 2010. Gaceta Oficial 
n. ${ }^{\circ} 39.382$ del 9 de marzo de 2010. Gaceta Oficial n. ${ }^{\circ} 39.416$ del 4 de mayo de 2010 (se reimprime por error material del ente emisor).

Ley Orgánica del Poder Popular. Gaceta Oficial n. ${ }^{\circ} 6011$ de 21 de diciembre de 2010.

Ley Orgánica del Poder Público Municipal. Gaceta Oficial n. 6015 de 28 de diciembre de 2010.

Ley Orgánica de las Comunas. Gaceta Oficial n. ${ }^{\circ} 6011$ de 21 de diciembre de 2010.

Ley Orgánica de Contraloría Social. Gaceta Oficial n. 6011 del 21 de diciembre de 2010.

Decreto de creación del Ministerio del Poder Popular para las Comunas y Protección Social el 17 de julio de 2009.

ÁLVAREZ, Tulio (2013). La Organización Comunal. Un poder popular que no se traduce en mayor participación. Revista SIC n. ${ }^{\circ}$ 752. Marzo 2013. Fundación Editorial Centro Gumilla. págs. 67-72. Caracas.

BREWER C, Allan (2009). Reforma Constitucional y Fraude a la Constitución (1999-2009). Academia de Ciencias Políticas y Sociales. Caracas.

- (2011). Introducción General al Régimen del Poder Popular y del Estado Comunal, en Leyes Orgánicas sobre el Poder Popular y el Estado

FREITEZ, Nelson (2013). La Comuna demanda una verdadera participación popular. Revista SIC n. ${ }^{\circ}$ 752. Marzo 2013. Fundación Centro Gumilla. Págs. 58-60. Caracas.

HERNÁNDEZ, José I. (2011). Descentralización y Poder Popular, en Leyes Orgánicas sobre el Poder Popular y el Estado Comunal. Editorial Jurídica Venezolana. Caracas.

HERNÁNDEZ, José I. y otros (2011). Sobre los vicios de inconstitucionalidad de la Ley Orgánica del Poder Popular, en Leyes Orgánicas sobre el Poder Popular y el Estado Comunal. Editorial Jurídica Venezolana. Caracas.

OCHOA, María A. (2011). Reformas del Poder Público Municipal al margen de la Constitución de la República Bolivariana de Venezuela. Vox Localis. U. I. M n. ${ }^{o}$ 35, Marzo 2011. En Vox Localis.net.

SÁNCHEZ M, Jorge (2010). Estado Federal, Estado Comunal y Consejo Federal de Gobierno. 
VILLEGAS M, José (2010). Derecho Administrativo Municipal. Editorial Sin Límite. San Cristóbal. Venezuela.

- (2010). Doscientos Siete años de municipalismo. FUNEDA-UCAT. Caracas.

- (2011). Jaque al Municipio Constitucional. La irrupción de la Comuna en el sistema territorial municipal. Anuario de Derecho Público. Centro de Estudios de Derecho Público de la Universidad Monteávila. Págs. 57-70 Caracas.

\section{Webgrafía:}

Entrevista al Econ. José Guerra: Las Comunas ¿Utopía o realidad?. Por Luis Rodríguez. Guayoyo en Letras.net/index.php/joomla.pages-iiicategories-list/49-guayoyocomunal/348 
